\title{
Beschneidungs-Urteil: Juristisch und rechtsethisch fragwürdig
}

VB verfassungsblog.de/beschneidungsurteil-juristisch-und-rechtsethisch-fragwrdig/

Hans Michael Heinig Mi 27 Jun 2012

Mi 27 Jun

2012

Ist die religiös motivierte Beschneidung eines minderjährigen Jungen als Körperverletzung strafbar? Das Landgericht Köln hat die Frage in einer Entscheidung vom Mai 2012 bejaht (Az. 151 Ns 169/11). Erst Ende Juni wurde die Entscheidung von einer breiteren Öffentlichkeit wahrgenommen. In der jüdischen Welt sorgt die Entscheidung für allerlei Irritationen. Folgt man dem Urteil, droht den in Deutschland lebenden Juden strafrechtliche Verfolgung, wenn sie der biblischen Tradition entsprechend Jungen acht Tage nach der Geburt beschneiden (Brit Mila). Die Zirkumzision ist im Judentum nicht irgendein randständiges Brauchtum, sondern für viele Juden ein wesentlicher Bestandteil jüdischer Identität. Die Brit Mila als Aufnahmeritual in die jüdische Gemeinschaft geht zurück auf die biblische Überlieferung des Bundschlusses Abrahams mit Gott (Gen 17, 1014). Doch auch im Islam wird die Beschneidung praktiziert. Sie gilt in der abrahamitischen Tradition als essentieller Ausdruck muslimischer Religionszugehörigkeit.

Das Landgericht Köln sieht in der Beschneidung mit Einwilligung der Eltern, aber ohne medizinische Indikation durch einen Arzt kunstgerecht vorgenommene Beschneidung eine nicht gerechtfertigte Körperverletzung. Der Angeklagte wurde im Ergebnis aber freigesprochen, weil die Rechtslage verworren sei und er einem unvermeidbaren Verbotsirrtum unterlag, so das Gericht. Doch grundsätzlich sei die Beschneidung strafbar.

Schaut man sich die Urteilsgründe genauer an, beschleichen einen Zweifel, ob das alles so richtig ist. Schaut man sich den religions- und kriminalpolitischen Subtext an, wachsen die Zweifel noch einmal erheblich an.

Zunächst zum Rechtlichen: der Streit um die Zulässigkeit der Jungenbeschneidung (die Strafbarkeit der Genitalverstümmelung von Mädchen steht außer Frage) dreht sich um die Frage, ob die Eltern rechtswirksam und damit rechtfertigend gemäß § 1627 BGB einwilligen können. Das Landgericht schließt das aus, weil die Beschneidung nicht dem Kindeswohl diene und begründet das mit drei Argumenten: Auf grundrechtlicher Ebene komme dem Rechtsgut der körperlichen Unversehrtheit ein absoluter Vorrang vor dem elterlichen Recht zur religiösen Erziehung zu. In der Rechtswertung sei die Beschneidung mit körperlicher Züchtigung, seelischen Verletzungen und anderen Entwürdigungen des Kindes (§ 1631 II BGB) gleichzusetzen. Und schließlich wird hervorgehoben, dass das Kind sich ja später von der Herkunftsreligion abwenden könnte; die Beschneidung stelle dann eine irreparable Beschädigung des Körpers dar.

Alle drei Begründungsschritte sind fragwürdig: Das Rechtsgut der körperlichen Unversehrtheit ist zwar von hoher Bedeutung und der Staat tut gut daran, sich schützend davor zu stellen. Doch schließt das eine grundrechtliche Kollisionslage, die nach den üblichen Regeln des Rechtsgüterausgleichs aufzulösen ist, nicht per se aus. In der Abwägung der Rechtsgüter ist dann auch die relativ geringe Intensität der körperlichen Beeinträchtigung und die hohe Bedeutung für die religiöse Identitätsbegründung (zumindest im Judentum) in Rechnung zu stellen. Die gesetzgeberische Wertung des $\S 1631$ II BGB bietet hingegen kaum Erkenntniswert. Kinder sollen nicht verprügelt werden - Schmerzzufügung und Demütigung sind keine erlaubten Erziehungsmittel, sagt das Gesetz. Der soziale Sinn und das physiologische Geschehen einer kunstgerecht durchgeführten Zirkumzision sind dann doch was anderes. Bleibt schließlich das Argument des bleibenden Stigmas. Der Beschnittene bleibt für sein Leben „gezeichnet“. Das stellt aber doch die Freiheit nicht in Frage, die inkulturierte religiöse Tradition später abzustreifen. Hier scheint ein Argument durch, dass zum Standardarsenal der antireligiösen Eiferer gehört: Über religiöse Zugehörigkeit könne erst der Mündige selbst entscheiden, weshalb man Kinder von allen religiösen Einflüssen fern halten müsse, damit es zu keiner Vorprägung kommt. Die Religionssoziologie weiß es besser: Selbstbestimmung über religiöse Zugehörigkeit setzt in der Regel ein Vertrautwerden mit religiöser Tradition voraus. Auch ist nicht recht erkennbar, warum eine Beschneidung dem Interesse, als Erwachsener über seine Religion zu entscheiden, zuwiderlaufen soll: geschätzt mind. ein Viertel der männlichen Weltbevölkerung ist beschnitten. Es gibt viele Gründe für eine Beschneidung. Vorzüge und 
Nachteile der Beschneidung werden in Fachkreisen intensiv diskutiert. In der Bewertung der Beschneidung von Männern und Jungen kommen eine Fülle kulturgeschichtlich-religiöser, medizinischer und ästhetischlebenspraktischer Aspekte zusammen. Im Raum stehen über tausende Jahre gepflegtes religiös-kulturelles Brauchtum, lange Traditionen antireligiöser und antisemitischer Polemiken, das spannungsgelandene Feld der sexuellen Lust und sexuellen Tabuisierungen, kulturelle Wahrnehmungen von Körperlichkeit, der biopolitische Zugriff des Staates auf den Körper und die alte Frage, inwieweit die freiheitlich-demokratische Staatsgewalt Mittel zur Durchsetzung einer rationalistischen Aufklärung sein soll und darf.

Liest man die Entscheidung des Landgerichts Köln, verwundert vor dem Hintergrund dieser komplexen Gemengelage die Unbekümmertheit, mit der das Gericht zu Werke geht. Die hier vorgeführte Konzentration auf die rechtstechnischen Fragen ist sicherlich vornehmster Ausdruck eines funktional ausdifferenzierten Rechtssystems; eine gewisse historische und kulturelle Sensibilität, ein Sinn für das, was man mit einem Urteil anrichtet, wünscht man sich aber doch von der Justiz. So stellt sich etwa die Frage, ob es sinnvoll ist, ausgerechnet den Arzt zu kriminalisieren, der die Beschneidung durchführt. Denn mit der Abdrängung solcher tradierten Praktiken in die Illegalität droht die Einschaltung von Pfuschern und damit sind echte Gesundheitsrisiken für die Kinder zu besorgen. Welches Signal geht weltweit davon aus, dass ausgerechnet in Deutschland nun ein strafrechtliches Beschneidungsverbot bestehen soll? Dass Juden für die Beschneidung Deutschland verlassen müssen, um ihre Religion entsprechend den eigenen Lehren leben zu können? Was sagt die Entscheidung den Muslimen, die in hohem Maße integrationswillig sind, aber bestimmte religiöse Traditionen doch pflegen wollen? Rechtsethisch und strafrechtlich wirft die Beschneidung von männlichen Minderjährigen schwerwiegende Fragen auf. So leicht wie das Landgericht Köln sollte es man sich bei der Beantwortung dieser Fragen nicht machen.

Hans Michael Heinig ist Professor für Öffentliches Recht und Kirchenrecht an der Universität Göttingen und leitet im Nebenamt das Kirchenrechtliche Institut der EKD.

LICENSED UNDER CC BY NC ND

SUGGESTED CITATION Heinig, Hans Michael: Beschneidungs-Urteil: Juristisch und rechtsethisch fragwürdig, VerfBlog, 2012/6/27, http://verfassungsblog.de/beschneidungsurteil-juristisch-und-rechtsethisch-fragwrdig/. 